\title{
Effect of Food Simulating Agents on the Hardness and Bond Strength of a Silicone Soft Liner to a Denture Base Acrylic Resin
}

\author{
A.A.R. Khaledi ${ }^{1}$, M. Bahrani ${ }^{2, *}$ and S. Shirzadi ${ }^{2}$ \\ ${ }^{I}$ Department of Prosthodontics, School of Dentistry, Shiraz University of Medical Sciences, Shiraz, Iran \\ ${ }^{2}$ School of Dentistry, Shiraz University of Medical Sciences, Shiraz, Iran
}

\begin{abstract}
Statement of the Problem: Bonding failure between acrylic resin and soft liner material and also gradual loss of soft liner resiliency over time are two impending challenges frequently recognized with a denture base embraced with a resilient liner. Since patients drink various beverages, it is crucial to assess the influences of these beverages on physical characteristics of soft liners. Purpose: This in vitro study envisioned to assess the influence of food simulating agents (FSA) on the hardness of a silicone soft liner by employing a Shore A durometer test and also evaluate its bond strength to a denture base resin by using tensile bond strength test. Materials and Methods: To test the hardness of samples, 50 rectangular samples $(40 \mathrm{~mm} \times 10 \mathrm{~mm} \times 3 \mathrm{~mm})$ were prepared from a heat-polymerized polymethyl methacrylate (Meliodent). Mollosil, a commercially available silicone resilient liner, was provided and applied on the specimens following the manufacturer's directions. In order to test tensile bond strength, 100 cylindrical specimens $(30 \mathrm{~mm} \times 10 \mathrm{~mm})$ were fabricated. The liners were added between specimens with the thicknesses of $3 \mathrm{~mm}$. The specimens were divided into 5 groups $(\mathrm{n}=10)$ and immersed in distilled water, heptane, citric acid, and $50 \%$ ethanol. For each test, we used 10 specimens as a baseline measurement; control group. All specimens were kept in dispersed containers at $37^{\circ} \mathrm{C}$ for 12 days and all solutions were changed every day. The hardness was verified using a Shore A durometer and the tensile bond strength was examined by an Instron testing machine at a cross-head speed of $5 \mathrm{~mm} / \mathrm{min}$. The records were analyzed employing one-way ANOVA, Tukey's HSD, and LSD tests. Results: The mean tensile bond strength \pm standard deviation (SD) for Mollosil was as follows for each group: $3.1 \pm 0.4$ (water), $1.8 \pm 0.4$ (citric acid), $3.0 \pm 0.4$ (heptane), $1.2 \pm 0.3$ (50\% ethanol), and $3.8 \pm 0.4$ (control). The hardness values for each group were: $28.7 \pm 2.11$ (water), $33.2 \pm 2.82$ (citric acid), $39.2 \pm 4.8$ (heptane), $32.3 \pm 3.56$ (50\% ethanol) and $22.2 \pm 2.08$ (control). Mean values for hardness indicated that all of the food simulating agents significantly increased hardness of the Mollosil soft liner compared to the control group $(\mathrm{p}<0.05)$. The results of tensile bond strength depicted that water and FSA decreased the bond strength of the soft liner denture base resin compared to the control group and it was statistically significant $(\mathrm{p}<0.05)$. Conclusion: The food simulating agents could influence the mechanical properties of silicone soft liners; hence, clinicians should inform their patients concerning their possible adverse effects and complications.
\end{abstract}

Keywords: Acrylic resin, food simulating agents, hardness, soft liner, tensile bond strength.

\section{INTRODUCTION}

Soft resilient liners or denture liners, due to their short- or long-term cushioning effects, are used in the inner surface of the denture base to improve the fitness of the denture, help to rehabilitate and condition inflamed tissues, and achieve more equal distribution of masticatory forces [1]. Soft liners are polymers that have a glass transition temperature $\left(T_{g}\right)$ lower than the mouth temperature. $\mathrm{T}_{\mathrm{g}}$ is the temperature at which a polymer ceases to be glassy and brittle, and changes to a rubber-like form [1-3]. These materials are generally used to provide a cushioning effect in patients with severe ridge resorption, severe bony undercuts, and congenital or acquired defects of the palate. These materials may also be employed as soft liners during the healing time following implant placement [1-7]. Soft liners are used to cover the

\footnotetext{
*Address correspondence to this author at the School of Dentistry, Shiraz University of Medical Sciences, Shiraz, Iran; Tel: +1(514)7781368;

E-mail: marmarbahr@yahoo.com
}

tissue-bearing aspect of a denture in order to improve its fit and retention, allowing a more homogenous distribution of occlusal loading forces [8-10].

Several types of resilient liners are used for prosthetic purposes. These liners are either acrylic resin-based or silicone-based. Both groups are available in auto-polymerized or heat-polymerized forms $[3,8,11]$. Consistent with another classification, soft liners are classified into two groups; short-term (tissue conditioners) and long-term. Long-term soft lining materials present numerous impediments related their usage such as hardening, water sorption, being infected with Candida albicans, bonding failure in denture base - soft liner layer, dimensional or color changes during their polymerization and use [10]. Hence, tear strength, tensile bond strength (TBS), elongation, and Shore A hardness (SH) should be examined to assess the characteristics of long-term soft liners [12].

One of the most challenging dilemma of using these materials is when the resilient denture liner fails to bond with the denture base [13]. Bonding failure produces an impend- 
ing surface for bacterial growth, plaque accumulation and calculus formation [10]. Any other positive characteristics of a denture liner would be inadequate when such bonding is absent. Different factors influence the bonding of resilient lining materials to the denture base such as water absorption, application of surface primer, and constitution of denture base [14]. The measurement of bond strength would be very imperative since the failure of soft-liners is often accredited to the failure of this bond. Many studies have assessed the bond strength of resilient liners bonded to denture base resin employing separate approaches such as peel, shear, or tensile tests [12, 15-25].

Long-term softness can be considered as another anticipated property of resilient liners. Hardness may impose stronger occlusal forces to the underlying mucosa which consequently would increase the clinical complaints of patients [26]. The soft liner should also provide a resistance to the absorption of oral fluids and also impede the release of ethanol and plasticizer into the saliva; the latter can gradually leave a stiffer, harder liner. A liner with higher degree of conversion (greater monomer incorporation into the polymer) will probably reveal less absorption and solubility and more stability over time [27-31]. Hardness and tensile properties generally describe the appropriateness of a material; a hard material with reduced tensile properties and elongation would be of little value to be used as a soft liner [32].

In clinical situations, soft liners are exposed to environments that would influence their hardness and bond strength $[21,33]$. To the best of author's knowledge, the effect of food simulating agents (FSA) on mechanical properties of silicone soft liner have not been adequately assessed. Therefore, this study investigated the effect of food simulating agents on TBS and hardness of a silicone soft liner.

\section{MATERIALS AND METHODS}

The materials used in this study are summarized in Table 1. We divided specimens into 5 groups of 10 specimens to test both hardness and TBS as Group 1: specimens tested for base line quantities (control group), Group 2: specimens dipped in distilled water for 12 days, Group 3: specimens dipped in heptane for 12 days, Group 4: specimens immersed in citric acid for 12 days, and Group 5: specimens immersed in an aqueous 50\% ethanol solution for 12 days. All of the immersions were laboratory solvents.

To test the hardness, we fabricated 50 rectangular samples with a cross-sectional area of $40 \mathrm{~mm}$ in length, $10 \mathrm{~mm}$ in height, and $3 \mathrm{~mm}$ in thickness for each group using a heatpolymerized poly methyl methacrylate (PMMA) denture base material. Two rectangular PMMA plates were prepared by investing stainless steel dies with a 3-mm-thick spacer in a denture flask. All dies and spacers were produced with the same dimensions concerning the standardization of the shape of the denture base blocks and the thickness of the resilient denture soft liners.

The dies and spacers were invested in hard though flexible, silicone rubber (Dentaurum; Langhorne, USA) to facilitate removal of the processed specimens from the flask. Specimens were prepared by processing the resilient denture liners against polymerized PMMA blocks. The acrylic resin denture base was prepared by mixing polymer and monomer for 1 minute, and then was packed into the mold using a stainless steel spacer. It was then processed in a water bath at $100^{\circ} \mathrm{C}$ for half an hour. Afterwards, the 2 polymerized PMMA specimens were removed from the flask and trimmed. Alcohol (Isopropanol 99.7\%; Voco, Cuxhaven, Germany) was applied to the surfaces and then followed by the adhesive (primer) that was left 1 minute to dry.

Table 1. Resilient liner material and denture base material tested.

\begin{tabular}{|c|c|c|}
\hline Product & Type of polymerization & Manufacturer \\
\hline \hline Meliodent & $\begin{array}{c}\text { Conventional } \\
\text { (heat-polymerized) }\end{array}$ & $\begin{array}{c}\text { Heraeus Kulzer, Hanau, } \\
\text { Germany }\end{array}$ \\
\hline Mollosil & $\begin{array}{c}\text { Autopolymerized } \\
\text { silicone-base resilient liner }\end{array}$ & $\begin{array}{c}\text { Detax GmbH \& Co., } \\
\text { KG, Germany }\end{array}$ \\
\hline
\end{tabular}

The stainless steel spacer was then removed from the flask. The PMMA blocks were replaced in the mold and the resilient denture liner materials were packed into the space left by the stainless steel spacers, trial packed, then polymerized. For Mollosil polymerization, the flasks were positioned under pressure in the flask press for half an hour. After polymerization, we removed the specimens from the flask and trimmed them with a sharp blade.

To assess the tensile strength, 10 pairs of cylindrical specimens (30 $\mathrm{mm}$ in height and $10 \mathrm{~mm}$ in diameter) were primed for each group by investing two stainless steel dies ahead of each other and a 3-mm-thickness spacer was located between them. The PMMA cylinders were fixed in the flasks as formerly defined for the hardness specimens. Later, the spacers were detached from the mold, and then the surfaces of the PMMA cylinders were treated by alcohol and the primer. Next, soft liner material was mixed, packed into the spaces between the acrylic cylinders and polymerized according to the manufacturer's directions. It was then placed under pressure for half an hour. The specimens were then detached from the flask and any flash was trimmed with a no. 1 sharp blade.

All specimens were kept in separate containers at $37^{\circ} \mathrm{C}$ for 12 days and the beverages were replaced by a fresh one every day. Studies reported that a regular drinker can consume 3.2 doses daily and each dose may last for 15 minutes; therefore, the 24-hour-storage time can simulate a duration of one month of regular drinking [34]. Accordingly, the 12day-immersion period in this study would represent one year consumption of that beverage. The hardness was evaluated by employing Shore A durometer tester (The Shore Instrument \& Mfg. Co. Inc.; Freeport, NY, USA), which was calibrated according to ASTM D2240. The results were reported in Shore units.

For the tensile test, specimens were placed under tension in a ZwickRoell testing machine (ZwickRoell; Germany) with a crosshead speed of $5 \mathrm{~mm} / \mathrm{min}$ till failure occurrence. Bond strength was calculated as maximum load (N) divided by the cross-sectional area $\left(\mathrm{mm}^{2}\right)$ of the specimen and recorded in mega Pascal unit (MPa). 
Table 2. Mean and SD of tensile bond strength (TBS) in MPa and hardness (Shore A) of Mollosil.

\begin{tabular}{|c|c|c|c|c|c|c|}
\hline & \multicolumn{3}{|c|}{ Hardness value } & \multicolumn{3}{c|}{ Bond strength value } \\
\hline & Mean & SD & P value & Mean & SD & P value \\
\hline \hline Heptane & 39.2 & 4.80 & $<0.001$ & 3.0 & 0.42 & 0.41 \\
\hline Citric acid & 33.2 & 2.82 & $<0.001$ & 1.8 & 0.001 \\
\hline $50 \%$ ethanol & 32.3 & 3.56 & $<0.001$ & 3.1 & 0.30 & $<0.001$ \\
\hline Distilled water & 28.7 & 2.11 & $<0.001$ & 3.8 & 0.40 & $<0.001$ \\
\hline Control & 22.2 & 2.08 & $<0.001$ & & $<0.001$ \\
\hline
\end{tabular}

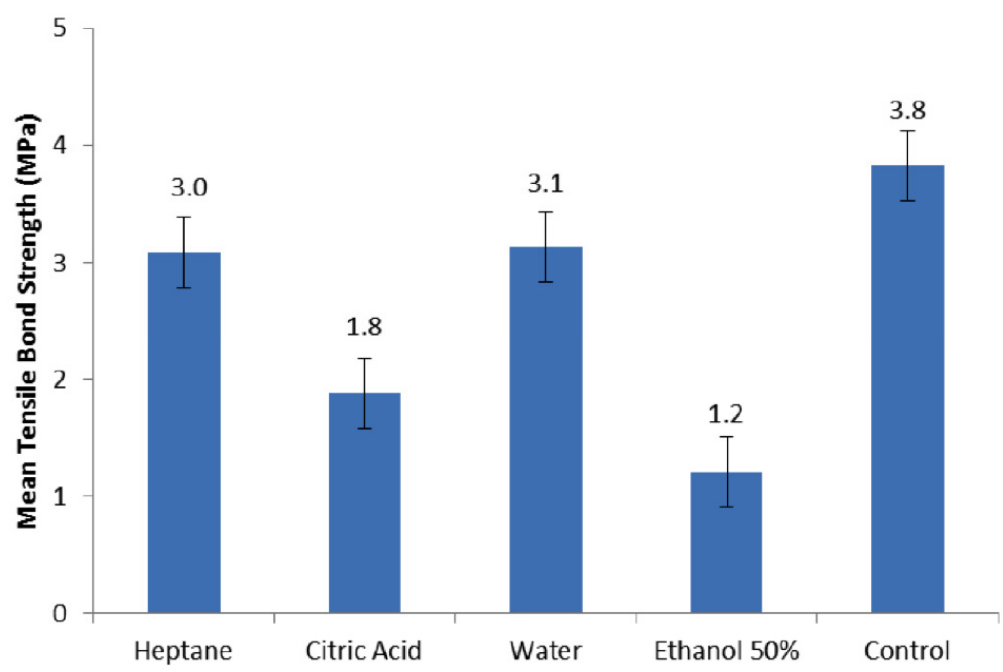

Fig. (1). Mean tensile bond strength (TBS) values and standard deviation (SD).

We substantiated the differences in the bond strength and hardness of the resilient liner material for the 5 groups. The resulting records were analyzed statistically using a one-way ANOVA and Tukey HSD post hoc test. The significance or non-significance of relations was considered on an alpha level 0.05 .

\section{RESULTS}

The results of hardness and tensile tests of specimens immersed in water and four food simulators for 12 days are shown in Table $\mathbf{2}$ and Figs. (1, 2). According to one-way ANOVA, we have observed significant interaction between food simulators in both hardness and bond strength tests $(\mathrm{p}<0.001)$.

The mean values of hardness in Table 2 indicated that all of the storage media showed significantly increased hardness of the Mollosil soft liner compared to the control group $(\mathrm{p}<0.05)$. Heptane had the most influence followed by citric acid, $50 \%$ ethanol and water.

The results of TBS showed that water and FSA significantly decreased the bond strength of the soft liner to the denture base resin compared to the control group $(\mathrm{p}<0.05)$. The greatest adverse effect was observed with $50 \%$ ethanol followed by citric acid, water and heptane.

A comparison of the $p$-values between the food simulators for hardness indicated significant differences between all groups $(p<0.05)$, except for the water-citric acid $(p=0.97)$ and ethanol-water $(p=0.11)$ groups. Hence, there were no statistically significant differences between these two groups. In terms of bond strength test, we observed an insignificant difference only between heptane and water $(p=0.99)$.

\section{DISCUSSION}

The authors were unable to identify any published data in the dental literature regarding the effect of food simulating agents on mechanical, physical and biological aspects of permanent silicone soft liners. Therefore, in this study we evaluated the effect of water, $50 \%$ ethanol, heptane and citric acid on hardness and bond strength of one type of silicone soft liner (Mollosil) to a denture base (Meliodent). The current study results showed that compared to baseline measurements (control group) the hardness of Mollosil increased after immersion of specimens in water and food simulating agents, however the TBS decreased. All the changes were significant compared to the control group.

The food simulating liquids used in current study for conditioning the specimens have been chosen on the basis of guidelines published by Food and Drug Administration (FDA, 1976, USA) [35]. Distilled water mimics the wet oral environment that saliva and water provide. Heptane simulates butter, fatty meats, and vegetable oils. The citric acid and ethanol solutions pretend certain beverages like alcohol, vegetables, fruits, candies, and syrups. Lactic acid would 


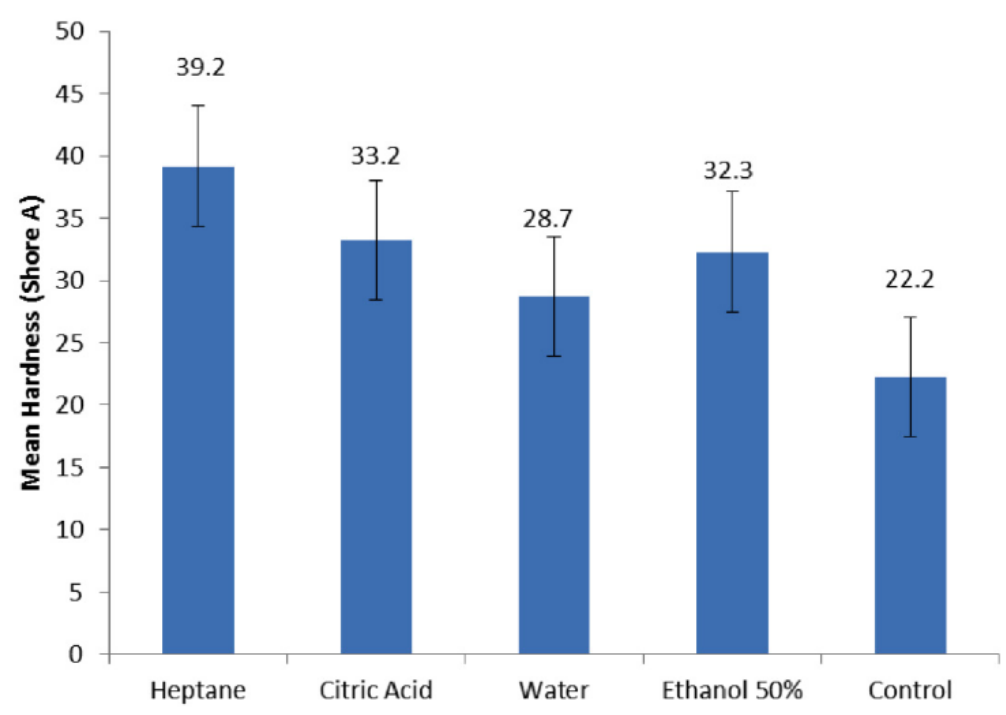

Fig. (2). Mean hardness values and standard deviation (SD).

mimic milk and dairy products. In real oral condition, acrylic resins and soft liners will be exposed either intermittently or continuously to these chemical substances. Intermittent exposure happens during eating or drinking periods until the time that teeth are brushed. On the other hand, continuous exposure may ensue when these agents are absorbed by debris like calculus or food particles that attach the restorations or may be produced by bacterial putrefaction of debris [36, 37]. It is reported that 3.2 doses of these agents are consumed by a regular drinker every day; each dose persists in the environment for 15 minutes. The 24-hour storage time would simulate one month of regular drinking [38], consequently, the 12-day-immersion period in this study epitomizes one year consumption of those beverages.

The modulus of elasticity (MOE) of the acrylic resin denture base (2400 MPa) is suggestively higher than those of the tissues on which it rests (1.25 to 5.0 MPa). Therefore, trauma or ulceration of the tissue would occur when the denture base is not stable or in instance that stress contemplates on the denture-supporting mucosa [39]. In these situations, soft liners provide a cushioning effect with a resiliency resembling the oral soft tissue $[39,40]$. Subsequently, they protect local concentration of stress and offer leveled distribution of functional load with good elasticity [33]. The SH test has been broadly used to appraise the elasticity of soft lining materials. This comparatively simple test defines the resistance to the indentation made by a rigid indenter on which a force is practiced [32]. Many studies have utilized the SH test with modifications for polymerization methods, aging, primer application, or pretreatment methods for soft liners $[8,9,12,32]$.

Moreover, several assessment methods such as peel strength [32], shear strength [41], and tensile strength tests [2] have been practiced to verify the bond strength of soft lining materials to denture bases. The TBS test has been documented as a proper routine, but the outcomes were not compatible due to the differences between assessment methodologies and different testing variables [8, 11, 32, 42].

The first variable is the inherent differences of the tested materials including the primers or adhesives and the adherent denture base resins that would alter the results $[10,43]$. The second variable is the different treatment methods of samples such as conditioning or the storage method used before testing that should be consistent in different studies [8,26, 44]. Finally, the TBS values may differ concerning the different bond strength testing variables, which comprised of specimen fixation methods, alignment of loading points, and crosshead speed $[10,16,45]$. The test results yielded from the studies performed with the first and second variables have provided broad information for a successful usage of the soft lining materials. However, a careful individuation is indispensible when comparing the TBS values attained from dissimilar test protocols; thus, matching the bond strengths of the soft lining materials in different studies is not a simple task.

When clinicians use the lining materials over a denture base resin, the presence of small bubbles in the bonded interface is usually unavoidable. Therefore, similar to current study, a larger standard deviation of the TBS values has been observed comparing the durometer $\mathrm{SH}$ values $[43,46]$. Hence, careful application of the primer or adhesive and careful application of the liner over the denture base should be considered to decrease the possibility of bubble inclusion. Furthermore, in TBS test, the vertical position of the tensile load axis which passes through the specimen center to the adherent surface is imperative. Otherwise, a twisting or shearing force will be exerted on the bonded surface that consequently causes imprecise TBS values, particularly when bubbles appear at the edge of the samples.

In the current study, the bond strength values of Mollosil were reduced considerably after water storage. Numerous factors have been described to influence the bond between resilient lining materials and denture bases. These parameters are comprised of aging in water, employing a primer with the lining material, and constitutes of the denture base material. The influence of water on the adhesive features of the resilient lining material to denture base material is of paramount significance to accomplish ultimate clinical success. When immersed, resilient denture liners endure two procedures; leaching out of plasticizers and other soluble materials, and also absorption of water and saliva [18]. The 
balance between these two procedures influences both the hardness and dimensional stability of the denture [46, 47]. When the liner material swells, stress is produced between bonding surfaces and the viscoelastic properties of the resilient liners alter [19]. Therefore, material becomes brittle and relocates the external loads to the bonding surface area [18]. After water storage and conditioning of the specimens with food simulating agents, Mollosil showed a significant reduction in bond strength. The reduction in the bond strength was the consequence of swelling and stress buildup at the bond interface or the result of altered viscoelastic properties of the resilient lining material. These issues probably rendered the material stiffer and transferred the external loads to the bond site. The results of the current study contradicted the results reported by Emmer et al. [16], Dootz et al. [22], and Craig and Gibbons [21]. These researchers concluded that tensile strength of resilient lining materials was increased after water storage. The results of the current study were in line with the results yielded by the study conducted by Polyzois [19] who reported that water storage have reduced the bond strength of the resilient liner. Nevertheless, a direct comparison of these studies could not be made due to the different mechanical tests and research protocols employed. In present study, it was experienced that alcohol had the most adverse effect on the bond strength followed by citric acid and heptane.

In the case of alcohol drinkers, the dentures are functioning in a corrosive environment. A the 3-5 year life time of the denture, assuming alcoholic drinks for 1 to 2 hours per day would result in a total 2000 to 3000 hours effect [48]. Vlissidis and Prombonas [48] have reported that alcohol alters the useful properties in two different ways. First, it creates stress crazing at highly loaded positions of the dentures that consequently reduces the static and dynamic strength of the base material. Second, alcohol has corrosive effects on the denture surface which may speed up the fatigue processes within the denture material, causing premature failure.

Yap et al. [49] have correlated the destruction mechanism of alcohol to the softening and damage of the polymer matrix which is removed partially from the surface. The partial removal of the matrix would lead to degradation of the filler-matrix interface and consequently impairing the mechanical properties. Accordingly, it may be advocated that alcoholic beverages would possibly compromise the functional longevity of the denture. The clinician should inform their patients concerning the possible effects of alcohol on their dentures, particularly if their prostheses are expected to function for a long time. Although citric acid is a weak acid, we have observed significantly decreased bond strength of the soft liner to resin material in this group compared to the control group. The water absorption of polymeric materials might be a potential justification for this decline after conditioning with this agent. Excessive water uptake could stimulate the breakdown causing a filler-matrix debonding. Silane hydrolysis and microcrack formation might also alter the mechanical properties of the material $[50,51]$.

In the current study, it was verified that after water storage, hardness of the soft liner increased significantly compared to the control group. This result was in line with those of Mese and Guzel [8] and Iwaki et al. [52]. The increase in hardness with storage is supposedly caused by the gradual leaching of plasticizers or other soluble contents from the soft lining materials $[2,11]$. The storage effect in the beverages had the hardness increase in the lining material which was in agreement with results reported by the study of Buudai et al. [53]. Several researchers have investigated the influence of other storage media on changes in viscoelasticity [47, 54-56], but none explained the difference between in vivo and in vitro changes that was reported by Jepson et al. [55] that found significantly less reductions in laboratory compliance after immersion in distilled water, saline, or artificial saliva compared to those perceived clinically. Further, evidence of an increased loss of plasticizer in vivo [57] suggested an improved clinical solvent effect. Distilled water, $50 \%$ alcohol, and $8 \%$ alcohol did not simulate clinical changes in compliance and were suitable as laboratory immersion solutions. Heptane seemed to offer propensity as a suitable laboratory immersing solution capable of reproducing the early rapid reduction and a later continued reduction in compliance which was characteristic of clinical changes. In our study heptane was a relatively aggressive solvent used as the fatty food simulator to assess the effects of indirect food additives that frequently involve highly cross-linked plasticized polymers. Its eminent effect on the looselystructured plasticized gel that characterized the experiment materials was predicted. It was clearly demonstrated by increase in hardness of the liners that were immersed in heptane solution and proposed the individual suitability of this solvent as part of a standard specification.

Although this study has delineated the changes in hardness and bond strength that resulted from solvent immersion, it did not identify the mechanism of these changes. Additional investigations to recognize the alternation in material composition after immersion in various solvents are prerequisite and may identify new methods to improve the properties of provisional soft liners.

In the current study, the bond strength of resilient denture liners was examined by tensile test. Softness of the resilient denture liners was measured based on their resistance to indentation in a material for 5 FSA. These tests used different forces compared to which the resilient denture lining materials were subjected clinically; however, this in vitro study could stipulate preliminary information, based on bond strength and hardness test results. Further clinical studies in longer periods are necessary to evaluate the impact of different processing procedures and also the influence of implicated time on chemical and physical properties of these materials.

\section{CONCLUSION}

Within the limitation of this study it could be concluded that:

1-The bond strength and hardness of the tested silicon soft liner were influenced by water storage.

2-The bond strength and hardness of the tested silicon soft liner significantly changed after exposure to food simulating agents.

3-Clinicians should caution patients regarding the possible effect of certain foods on dentures relined by resilient liners. 


\section{CONFLICT OF INTEREST}

The authors confirm that this article content has no conflict of interest.

\section{ACKNOWLEDGEMENTS}

The authors would like to thank the Vice-Chancellery of Shiraz University of Medical Science for supporting this research (Grant\#6026). Bahrani.

This article is based on a thesis by Dr. S. Shirzadi and M.

\section{REFERENCES}

[1] Zarb GA, Bolender CL, Eckert S, Jacob R, Fenton A, MericskeStern R. Prosthodontic treatment for edentulous patients. Complete dentures and implant-supported prostheses $12^{\text {th }}$ ed., St Louis: Mosby 2004.

[2] León BL, Del Bel Cury AA, Garcia RRC. Water sorption, solubility, and tensile bond strength of resilient denture lining materials polymerized by different methods after thermal cycling. J Prosthet Dent 2005; 93(3): 282-7.

[3] Maeda T, Hong G, Sadamori S, Hamada T, Akagawa Y. Durability of peel bond of resilient denture liners to acrylic denture base resin. J Prosthodont Res 2012; 56(2): 136-41.

[4] Powers JM, Sakaguchi RL, Craig RGRdm. Craig's restorative dental materials. $12^{\text {th }}$ ed. Powers JM, Sakaguchi RL, Eds. St. Louis, Mo.; London: Mosby Elsevier 2006.

[5] Wright PS. The success and failure of denture soft-lining materials in clinical use. J Dent 1984; 12(4): 319-27.

[6] Singh K, Chand P, Singh BP, Patel CB. Study of the effect of surface treatment on the long term effectiveness of tissue conditioner. J Oral Sci 2010; 52(2): 261-5.

[7] Murata H, Hamada T, Djulaeha E, Nikawa H. Rheology of tissue conditioners. J Prosthet Dent 1998; 79(2): 188-99.

[8] Mese A, Guzel KG. Effect of storage duration on the hardness and tensile bond strength of silicone- and acrylic resin-based resilient denture liners to a processed denture base acrylic resin. J Prosthet Dent 2008; 99(2): 153-9.

[9] Polyzois GL, Frangou MJ. Influence of curing method, sealer, and water storage on the hardness of a soft lining material over time. J Prosthodont 2001; 10(1): 42-5.

[10] Kawano F, Dootz ER, Koran A, Craig RG. Comparison of bond strength of six soft denture liners to denture base resin. J Prosthet Dent 1992; 68(2): 368-71.

[11] El-Hadary A, Drummond JL. Comparative study of water sorption, solubility, and tensile bond strength of two soft lining materials. J Prosthet Dent 2000; 83(3): 356-61.

[12] Dootz ER, Koran A, Craig RG. Comparison of the physical properties of 11 soft denture liners. J Prosthet Dent 1992; 67(5): 707-12.

[13] Sinobad D, Murphy WM, Huggett R, Brooks S. Bond strength and rupture properties of some soft denture liners. J Oral Rehabil 1992; 19(2): 151-60.

[14] Kulak-Ozkan Y, Sertgoz A, Gedik H. Effect of thermocycling on tensile bond strength of six silicone-based, resilient denture liners. J Prosthet Dent 2003; 89(3): 303-10.

[15] Kutay O. Comparison of tensile and peel bond strengths of resilient liners. J Prosthet Dent 1994; 71(5): 525-31.

[16] Emmer TJ, Vaidynathan J, Vaidynathan TK. Bond strength of permanent soft denture liners bonded to the denture base. J Prosthet Dent 199; 74(6): 595-601.

[17] Sertgöz A, Kulak Y, Gedik H, Taskonak B. The effect of thermocycling on peel strength of six soft lining materials. J Oral Rehabil 2002; 29(6): 583-7.

[18] Aydin AK, Terzioğlu H, Akinay AE, Ulubayram K, Hasirci N. Bond strength and failure analysis of lining materials to denture resin. Dent Mater 1999; 15(3): 211-8.

[19] Polyzois GL. Adhesion properties of resilient lining materials bonded to light-cured denture resins. J Prosthet Dent 1992; 68(5): 854-8.
[20] Khan Z, Martin J, Collard S. Adhesion characteristics of visible light-cured denture base material bonded to resilient lining materials. J Prosthet Dent 1989; 62(2): 196-200.

[21] Craig RG, Gibbons P. Properties of resilient denture liners. J Am Dent Assoc 1961; 63: 382-90.

[22] Dootz ER, Koran A, Craig RG. Physical property comparison of 11 soft denture lining materials as a function of accelerated aging. J Prosthet Dent 1993; 69(1): 114-9.

[23] Jepson NJ, McCabe JF, Storer R. The clinical serviceability of two permanent denture soft linings. Br Dent J 1994;177(1): 11-6.

[24] Meșe A, Güzel KG, Uysal E. Effect of storage duration on tensile bond strength of acrylic or silicone-based soft denture liners to a processed denture base polymer. Acta Odontol Scand 2005; 63(1): 31-5.

[25] Waters MG, Jagger RG, Winter RW. Effect of surface modified fillers on the water absorption of a (RTV) silicone denture soft lining material. J Dent 1996; 24(4): 297-300.

[26] Pinto JR, Mesquita MF, Henriques GE, de Arruda Nóbilo MA. Effect of thermocycling on bond strength and elasticity of 4 longterm soft denture liners. J Prosthet Dent 2002; 88(5): 516-21.

[27] Parr GR, Rueggeberg FA. In vitro hardness, water sorption, and resin solubility of laboratory-processed and autopolymerized longterm resilient denture liners over one year of water storage. J Prosthet Dent 2002; 88(2): 139-44.

[28] Canay S, Hersek N, Tulunoğlu I, Uzun G. Evaluation of colour and hardness changes of soft lining materials in food colorant solutions. J Oral Rehabil 1999; 26(10): 821-9.

[29] Wagner WC, Kawano F, Dootz ER, Koran A. Dynamic viscoelastic properties of processed soft denture liners: Part II-Effect of aging. J Prosthet Dent 1995; 74(3): 299-304.

[30] Jepson NJ, McCabe JF, Storer R. Evaluation of the viscoelastic properties of denture soft lining materials. J Dent 1993; 21(3): 16370.

[31] Hekimoğlu C, Anil N. The effect of accelerated ageing on the mechanical properties of soft denture lining materials. J Oral Rehabil 1999; 26(9): 745-8.

[32] Waters MG, Jagger RG. Mechanical properties of an experimental denture soft lining material. J Dent 1999; 27(3):197-202.

[33] Qudah S, Harrison A, Huggett R. Soft lining materials in prosthetic dentistry: a review. Int J Prosthodont 1990; 3(5): 477-83.

[34] Leite VM, Pisani MX, Paranhos HF, Souza RF, Silva-Lovato CH. Effect of ageing and immersion in different beverages on properties of denture lining materials. J Appl Oral Sci 2010; 18(4): 3 72-8.

[35] Yap AU, Chew CL, Ong LF, Teoh SH. Environmental damage and occlusal contact area wear of composite restoratives. J Oral Rehab 2002; 29(1): 87-97.

[36] Yesilyurt C, Yoldas O, Altintas SH, Kusgoz A. Effects of foodsimulating liquids on the mechanical properties of a silorane-based dental composite. Dent Mater J 2009; 28(3): 362-7.

[37] Lee SY, Greener EH, Mueller HJ, Chiu CH. Effect of food and oral simulating fluids on dentine bond and composite strength. J Dent 1994; 22(6): 352-9.

[38] Guler AU, Yilmaz F, Kulunk T, Guler E, Kurt S. Effects of different drinks on stainability of resin composite provisional restorative materials. J Prosthet Dent 2005; 94(2): 118-24.

[39] Sato Y, Abe Y, Okane H, Tsuga K. Finite element analysis of stress relaxation in soft denture liner. J Oral Rehabil 2000; 27(8): 660-3.

[40] Kawano F, Tada N, Nagao K, Matsumoto N. The influence of soft lining materials on pressure distribution. J Prosthet Dent 1991; 65(4): 567-75.

[41] Ahmad F, Dent M, Yunus N. Shear bond strength of two chemically different denture base polymers to reline materials. J Prosthodont 2009; 18(7): 596-602.

[42] Hong G, Murata H, Hamada T. Relationship between plasticizer content and tensile bond strength of soft denture liners to a denture base resin. Dent Mater J 2004; 23(2): 94-9.

[43] McCabe JF, Carrick TE, Kamohara H. Adhesive bond strength and compliance for denture soft lining materials. Biomaterials 2002; 23(5): 1347-52.

[44] Takahashi JM, Consani RL, Henriques GE, Nóbilo MA, Mesquita MF. Effect of accelerated aging on permanent deformation and tensile bond strength of autopolymerizing soft denture liners. J Prosthodont 2011; 20(3): 200-4.

[45] Mutluay MM, Ruyter IE. Evaluation of bond strength of soft relining materials to denture base polymers. Dent Mater 2007; 23(11): 1373-81. 
[46] Braden M, Wright PS. Water absorption and water solubility of soft lining materials for acrylic dentures. J Dent Res 1983; 62(6): 764-8.

[47] Kazanji MN, Watkinson AC. Soft lining materials: their absorption of, and solubility in, artificial saliva. Br Dent J 1988; 165(3): 91-4.

[48] Vlissidis D, Prombonas A. Effect of alcoholic drinks on surface quality and mechanical strength of denture base materials. J Biomed Mater Res 1997; 38(3): 257-61.

[49] Yap AU, Mah MK, Lye CP, Loh PL. Influence of dietary simulating solvents on the hardness of provisional restorative materials. Dent Mater 2004; 20(4): 370-6.

[50] Yap AU, Tan DT, Goh BK, Kuah HG, Goh M. Effect of foodsimulating liquids on the flexural strength of composite and polyacid-modified composite restoratives. Oper Dent 2000; 25(3): 202-8.

[51] Yap AU, Lee MK, Chung SM, Tsai KT, Lim CT. Effect of foodsimulating liquids on the shear punch strength of composite and polyacid-modified composite restoratives. Oper Dent 2003; 28(5): $529-34$.
[52] Iwaki M, Akiba N, Minakuchi S, Takahashi H. Influence of methyl mercaptan at early setting stages on the properties of self curing addition silicone resilient denture lining materials. J Prosthodont Res 2009; 53(4): 161-5.

[53] Buudai S, Ohtani T, Maeda Y, Ishii K, Nokubi T. Hardness of denture reline materials polymerized with different techniques. J Osaka Univ Dent Sch 1995; 35: 39-44.

[54] Davenport JC, Wilson HJ, Basker RM. The compatibility of tissue conditioners with denture cleaners and chlorhexidine. J Dent 1978; 6(3): $239-46$

[55] Jepson NJ, McCabe JF, Storer R. Age changes in the viscoelasticity of a temporary soft lining material. J Dent 1993; 21(4): 244-7.

[56] Murata H, McCabe JF, Jepson NJ, Hamada T. The influence of immersion solutions on the viscoelasticity of temporary soft lining materials. Dent Mater 1996; 12(1): 19-24.

[57] Graham BS, Jones DW, Sutow EJ. An in vivo and in vitro study of the loss of plasticizer from soft polymer-gel materials. J Dent Res 1991; 70(5): 870-3.

Received: June 27,2015

Revised: July 16,2015

Accepted: September 15, 2015

(C) Khaledi et al.; Licensee Bentham Open.

This is an open access article licensed under the terms of the (https://creativecommons.org/licenses/by/4.0/legalcode), which permits unrestricted, noncommercial use, distribution and reproduction in any medium, provided the work is properly cited. 